YYÜ Eğitim Fakültesi Dergisi (YYU Journal of Education Faculty), 2019; 16(1):678-693, http://efdergi.yyu.edu.tr

\title{
Sosyal Bilgiler Öğretmen Adaylarının Proje Tabanlı Öğrenme (PTÖ) Algılarının
}

\section{İncelenmesi}

\section{Yavuz AKBAŞ ${ }^{*}$, Miraç AYDIN**}

Öz: Günümüzde eğitimde, 21. Yüzyıl becerileri olarak adlandırılan ve bilginin edinilmesi yerine üretilmesini temel alan anlayış ön planda bulunmaktadır. Bu becerilerin kazanılması için önerilen yöntemlerden biri projedir. Ancak literatürde belirtildiği üzere, öğretmen adaylarının bu konuda yeterlikleri, deneyimleri ve ortaya koydukları ürünlerin niteliği istenen düzeyde değildir. $\mathrm{Bu}$ olumsuz durumun temelinde öğretmen adaylarının proje algısının bulunduğu düşünülmektedir. $\mathrm{Bu}$ bağlamda çalışmanın amacı proje konusunda yeterli deneyime sahip olmayan sosyal bilgiler öğretmen adaylarının sahip oldukları proje algılarını ortaya çıkarmaktır. Çalışmada tarama modeli (survey) kullanılmıştır. 2014-2015 eğitimöğretim yılında Karadeniz Teknik Üniversitesi, Sosyal Bilgiler Öğretmenliği programında üçüncü sınıfta öğrenim gören 145 öğretmen adayı çalışmanın örneklemini oluşturmaktadır. Veri toplamak amacıyla, öğretmen adaylarına bilimsel araştırma yöntemleri dersi öncesinde zihin haritası çizdirilmiş ve açık uçlu anket soruları yöneltilmiştir. Elde edilen nitel veriler çözümlenerek tablo ve grafik eşliğinde sunulmuştur. Araştırma sonunda öğretmen adaylarının projeyi daha çok bir öğretim materyali tasarlama veya derste konuların öğretiminde kullanılan bir yöntem veya teknik olarak algıladıkları görülmüştür. Ortaya çıkan sonuçlar çerçevesinde uygulayıcılara ve araştırmacılara yönelik öneriler yapılmıştır.

Anahtar kelimeler: Proje Tabanlı Öğrenme, Proje, Öğretmen Adayı, Alg1

\section{Exploring Pre-service Social Studies Teachers’ Perceptions of Project Based}

\section{Learning(PBL)}

Abstract: We are living in a technology driven fast moving age in which students need 21st century skills to be successful in work and daily life. Project Based Learning (PBL) that requires students to make a project is recommended to achieve the aforementioned skills. One of the focuses of the research is teachers' and students' perceptions of the benefits and challenges of PBL and project. According to the research, these perceptions effect teachers

\footnotetext{
*Doç. Dr., Trabzon Üniversitesi, Fatih Eğitim Fakültesi, Türkçe ve Sosyal Bilimler Eğitimi Bölümü, Email:yakbas@trabzon.edu.tr Orcid No: 0000-0002-3500-4701.

** Doç. Dr.,Trabzon Üniversitesi, Fatih Eğitim Fakültesi, Matematik ve Fen Bilimleri Bölümü, Email: miracaydin81@gmail.com._Orcid No: $\underline{0000-0001-9616-5341}$
} 
and teacher candidates' qualifications, experiences and artifacts. The aim of this study was to identify perceptions of pre-service social studies teachers who have not sufficient experiences in the projects. The survey method was used in the study. A total of 145 students comprised the participants. This study was conducted in an undergraduate social science teacher education program at Faculty of Education in Trabzon, Turkey during autumn semester of the 2014-2015 school year. The open ended questions were administered and mind maps were asked to the participants to define what they perceived as project. A qualitative analysis was conducted and results were presented in graphs and tables. This study concluded that teacher candidates perceive projects as for preparing teaching materials and an instruction technique to teach subject matter of social studies. Recommendations for practitioners and researchers are presented.

Keywords: Project Based Learning, Project, Teacher Candidate, Perception.

\section{Giriş}

İçinde yaşadığımız yüzyılda 21. yüzyıl becerileri olarak adlandırılan ve bilginin tamamı yerine temel düzeyde edinimini temel alan, eleştirel düşünme ve yaratıcılık gibi üst düzey düşünme becerilerini kazandırmaya çalışan ve öğrenenleri teknoloji desteğinde işbirliği yapmaya sevk eden bir anlayış ön planda bulunmaktadır (URL, 2018). Okul öncesinden üniversiteye kadar (K-12) öğrencileri proje yaptırarak aktif bir şekilde günlük yaşama dâhil eden Proje Tabanlı Öğrenme (PTÖ) 21. yüzyıl becerilerinin kazanılması için önemli imkânlar sunmaktadır (Metz, 2015). PTÖ’ nün odağında bulunan proje (Wengrowicz vd., 2014) öğrenmeye katkı sağlamak amacıyla kullanılabileceği gibi öğretmenlerin sınıflarında karşılaştıkları problemleri çözmek amacıyla da kullanılabilmektedir.

İlgili literatür incelendiğinde PTÖ’nün (ve proje hazırlamanın) sağladığı faydalar kadar öğrenme ortamına uygulanmasında karşılaşılan zorluklar üzerine yapılmış çalışmalara rastlanmaktadir. Rogers, Cross, Gresalfi, Trauth-Nare ve Buck (2011) siniflarında ilk defa PTÖ’yü uygulayan öğretmenlerin uyum sürecinde yaşadığı zorlukları, zorlukların nedenlerini ve aşmak için yaptıklarını incelemişlerdir. Buna göre yaşanan zorlukların temelinde projenin uğraştırıcı doğası ve proje algısı olduğu, algının deneyimler tarafından şekillendirildiği ve öğretmenlerin PTÖ’yü kullanmaya açık olma (openness) veya karşı çıkma (resistance) durumlarının algılardan etkilendiği tespit edilmiştir. Proje algısı proje konusunda yaşanmış deneyimlerin zihinde farklı biçimlerde örgütlenmesi anlamında kullanılmaktadır. Yaşanan zorluklar ortaya konulan ürünlerin niteliğini düşürmekte, yıllık ödev veya çeşitli 
kaynaklardan derleme şeklindeki bir internet araştırması yapmak proje yapmak ile eşdeğer sayılmaktadır. Oysa ki başarılı bir PTÖ’nün sahip olması gereken beş temel özellikten birisinin projenin özelliklerini yansıtan somut bir ürün olduğu belirtilmektedir (Blumenfeld vd., 1991; Krajcik, 2015). Marshall vd. (2010) proje konusunda yeterli düzeyde deneyimi olmayan öğretmen adaylarının PTÖ ile ilgili kavramaları (conceptions) ve uygulamaları (enactments) üzerine yaptığı çalışmada çoğunun projenin genel ve herkes tarafından bilinen yüzeysel özelliklerini (keşfetme, grup çalışması içerme, uzun süreli olma vb.) bildiğini; fakat projeye ait karakteristik özelliklerini (araştırma problemi içerme, somut ürün ile sonuçlanma, günlük yaşam ile ilişkili görevler içerme vb.) bilmediklerini tespit etmişlerdir. Bulunuz (2011), öğretmen adaylarının proje konusundaki deneyimlerinin niteliğini sorgulamış ve yeterli düzeyde olmadığı sonucuna ulaşmıştır. Önen vd. (2010)'nin proje konusunda çeşitli deneyimleri olan 104 Anadolu Öğretmen Lisesi öğretmeni ile yaptıkları ve projenin tanımını sordukları bir araştırmada, öğretmenlerin \%90'nının soruyu cevaplayamadıkları tespit edilmiştir.

Çalışmalar incelendiğinde proje uygulama sürecinde karşılaşılan zorlukların yetersiz deneyimden kaynaklanan algılar olduğu, bu algıların proje çıktılarını olumsuz yönde etkilediği ancak proje konusunda herhangi bir deneyime sahip olmayan öğretmen adaylarının algılarının nasıl olduğu üzerinde durulmadığı görülmektedir.

Öğretmen adaylarının son zamanlarda giderek yaygınlaşan PTÖ ve projeleri (Hou vd., 2010) mesleğe başlamadan önce öğrenmeleri gerekmektedir (Zafirov, 2013). Öğretmenlik mesleğini yürütecek olan adayların lisans eğitimleri sırasında proje yaklaşımını kullanmaları veya araştırma yapmaları öğretmenlik yaşantılarında eğitim ile ilgili karşılaştıkları problemleri çözmelerine katkı sağlamayacaktır. $\mathrm{Bu}$ bağlamda gelecekte insanlığın problemlerine çözüm bulacak mühendis, bilim insanı gibi insan kaynaklarını yetiştirecek olan öğretmen adaylarının (Karışan ve Bakırcı, 2018) proje ve araştırma konusundaki yeterlikleri kuşkusuz çok önemlidir. Acun (2010) araştırmayı öğrenmenin, aslında öğrenmeyi öğrenme olduğunu belirterek konunun önemini şöyle ifade etmiştir: "Bilgi birikiminde çok hızlı değişmelerin olduğu günümüzde var olan bilgi ve becerileri kazanmak tek başına yeterli değildir... O yüzden öğrenmeyi bilen (araştırma yapabilen) meslek sahipleri diğerlerinden daha başarılı olmaktadır”. Öğretmen adaylarına lisans eğitimleri sırasında verilecek proje eğitimleri öncesi çeşitli proje deneyimlerine sahip olanların algıları yapılan çalışmalarla ortaya çıkarıldığı için kurs hedefleri ve içerikleri bu doğrultuda düzenlenebilir. Ancak hiç 
YYÜ Eğitim Fakültesi Dergisi (YYU Journal of Education Faculty), 2019; 16(1):678-693, http://efdergi.yyu.edu.tr

deneyimi olmayan öğretmen adaylarına uygulanacak kurs içeriğinin oluşturulması için bunların proje algılarının tespit edilmesi önem arz etmektedir.

$\mathrm{Bu}$ çalışmada proje konusunda yeterli deneyime sahip olmayan sosyal bilgiler öğretmen adaylarının sahip oldukları proje algılarını ortaya çıkarmak amaçlanmıştır.

\section{Yöntem}

\section{Araştırmanın Deseni}

Araştırmada tarama yöntemi (survey) kullanılmıştır. Tarama yöntemi, araştırılan durum ile ilgili "ne" sorusuna yanıt vermektedir (Kaptan, 1998). Bu yöntem çok sayıda kişiyi ilgilendiren bir durumu betimlemek amacıyla frekanslar ve/veya yüzdeler kullanılarak uygulanır (Karasar, 2014). Ayrıca olayları ve olguları kendi akışı içinde, onlara müdahalede bulunmadan geniş bir alanı tarayarak betimlemeye çalışır (Yin, 2003). Bu çalışmada, proje konusunda yeterli deneyimi olmayan sosyal bilgiler öğretmen adaylarının proje algısı tanımlandığı için tarama yönetimi tercih edilmiştir.

\section{Örneklem}

Karadeniz Teknik Üniversitesi Fatih Eğitim Fakültesi İlköğretim Bölümü Sosyal Bilgiler Öğretmenliği programında 3. Sınıfta öğrenim gören 145 öğretmen adayı çalışmanın örneklemini oluşturmaktadır. Glesne (2011) geniş ancak yüzeysel bir analiz için çok kişi ile az veri toplanması gerektiğini buna karşılık derin bir analiz için az sayıda kişi ile uzun süreli çalışılması gerektiğini ifade etmektedir. Buna göre Bilimsel Araştırma Yöntemlerini alan her bir öğretmen adayının tamamına ulaşılmış ve ölçme araçları uygulanmıştır.

\section{Uygulamanın yapılması}

Öğretmen adaylarına bilimsel araştırma yöntemleri dersini almadan hemen önce proje algılarını ortaya çıkarmak için zihin haritası çizdirilmiş, açıklamalar yazdırılmış ve açık uçlu anket soruları yöneltilmiştir.

\section{Veri Toplama Araçları}

Çalışmada veri toplama aracı olarak zihin haritaları ve açık uçlu sorulardan oluşan bir anket kullanılmıştır.

Zihin haritaları bireyin bir kavram ile ilgili sahip olduğu bilgi düzeyini belirlemek için kullanılan etkili bir tekniktir (Buzan, 2005). Öğretmen adaylarına öncelikle proje kavramı ile 
ilgili beyin fırtınası yaptırılmış, daha sonra ortaya çıkan ifadelerin proje kavramı merkezinde kâğıda yazılması istenmiştir. Son olarak öğretmen adayları zihin haritasını açıklayan yazılı ifadeler eklemişlerdir.

Anket dört açık uçlu sorudan oluşmaktadır. Öğretmen adaylarına öncelikle proje yapıp yapmadıkları, yaptıysalar projeyle ilgili detaylar sorulmuştur. İkinci soru projenin tanımını içermektedir. Üçüncü soruda projenin özellikleri ve ana unsurları sorulmuştur. Son soru ise "meslek yaşantınızda proje yöntemini kullanmayı düşünseniz nasıl bir yol izlerdiniz?” şeklinde yöneltilmiştir.

Bilindiği gibi anketlerin geçerlik çalışmaları testler için tanımlananlara benzemektedir. Ancak testler için gerçekleştirilebilen çoğu çalışmayı açık uçlu anketler için uygulamak mümkün görünmemektedir (Kaptan, 1998). Bu çerçevede, ankettin kapsam ve görünüş geçerliğini sağlamak için, sorular alan eğitiminde araştırmalar yürüten akademisyenlere inceletilmiştir. Anketin yapı geçerliğini sağlamak için sorularda proje algısını ölçmede kullanılan üç boyuta (projenin tanımı, projenin karakteristik özellikleri, projenin öğretimde nasıl işe koşulabileceği ve karşılaşılması muhtemel zorluklar) yer verilmiştir. Bu boyutlar proje algısını ölçen çalışmalarda (Marshall, Petrosino, ve Martin, 2010; Rogers vd., 2011) tanımlanmıştır. Anket açık uçlu sorulardan oluştuğu için, elde edilen nitel verilerin analizinde ortaya çıkan durumun güvenirliğini sağlamak için puanlayıcılar/kodlayıcılar arası tutarlılık belirleme yoluna gidilmiştir. Bu konuda detaylı bilgi veri analizi bölümünde verilmiştir.

\section{Veri Analizi}

Çalışmada hem zihin haritaları hem de açık uçlu sorulardan nitel veriler elde edildiği için nitel veri analizinde takip edilen aşamalar doğrultusunda analiz gerçekleştirilmiştir. Bu doğrultuda öğretmen adaylarının zihin haritasında kullandıkları ifadeler ve bunları açıklamak için yazdıkları yazılar ve açık uçlu sorulara verdikleri cevaplar birlikte ele alınmıştır. Veriler öncelikle NVivo 9.0 paket programı içinde bir araya getirilmiştir. Daha sonra Miles, Huberman ve Saldana (2015)'nın tavsiye ettiği biçimde kodlama ve tema oluşturma (Data condensation) tablo ve grafik eşliğinde verileri sunma (Data display) ve verinin altında yatan anlamı ortaya çıkarıp doğrulama (Conclusions: Drawing and verifying) işlemleri gerçekleştirilmiştir. Proje kavramı ile ilgili algıları koyan 24 ifade tespit edilmiş ve bunların tekrar etme sıklıkları belirlenmiştir. Ardından bu kelimeler belirli özelliklerine göre 
YYÜ Eğitim Fakültesi Dergisi (YYU Journal of Education Faculty), 2019; 16(1):678-693, http://efdergi.yyu.edu.tr

gruplandırılarak 8 tema oluşturulmuş ve bir model eşliğinde sunulmuştur. Böylece veriler içerisinden anlam örüntüleri (pattern) belirlenmeye çalışılmıştır.

Kodlayıcılar arası güvenirliği sağlamak için çalışmanın yazarları bağımsız olarak ifadeleri ve temaları oluşturmuş ve sonra bir araya gelerek ifadeler ve temalar arasındaki uyum sağlanmış, fikir birliğine varılamayan ifade ve temalar tartışılmış ve ortak bir mutabakata varılarak kod ve temalara son hali verilmiştir.

\section{Bulgular}

Sosyal bilgiler öğretmen adaylarının proje konusundaki algılarının incelendiği bu çalışmada zihin haritasında proje kavramına karşılık olarak yazılan kavram - ifadeler ve tekrar etme sıklıkları (frekanslar) Tablo 1 ve Şekil 1'de sunulmuştur.

Tablo 1.

Projeyi ifade eden kelimeler ve tekrar edilme sıklıkları

\begin{tabular}{lll}
\hline No & İfade/kelime & Frekans \\
\hline 7 & Grup Çalışması & 43 \\
23 & Yaratıcılık/Özgünlük & 27 \\
9 & Problem/sorun çözme & 25 \\
19 & Üretim & 21 \\
3 & Zor bir uğraş & 15 \\
20 & Tasarım & 15 \\
24 & Yenilik & 15 \\
4 & Planlı çalışma & 13 \\
5 & Sınırlı sürede tamamlama & 11 \\
10 & Problem & 11 \\
18 & İcat etme & 11 \\
2 & Öğretim materyali geliştirme & 10 \\
14 & Bilim ve bilimsellik & 9 \\
8 & Sorumluluk & 8 \\
15 & Deney yapma & 8 \\
1 & Yöntem/Teknik & 6 \\
12 & Gözlem yapma & 6
\end{tabular}


YYÜ Eğitim Fakültesi Dergisi (YYU Journal of Education Faculty), 2019; 16(1):678-693, http://efdergi.yyu.edu.tr

$16 \quad$ Keşfetme

17 Buluş yapma 5

22 Yeni bilgi 5

6 Yoğun çalışma

11 Uygulama

21 Teknoloji

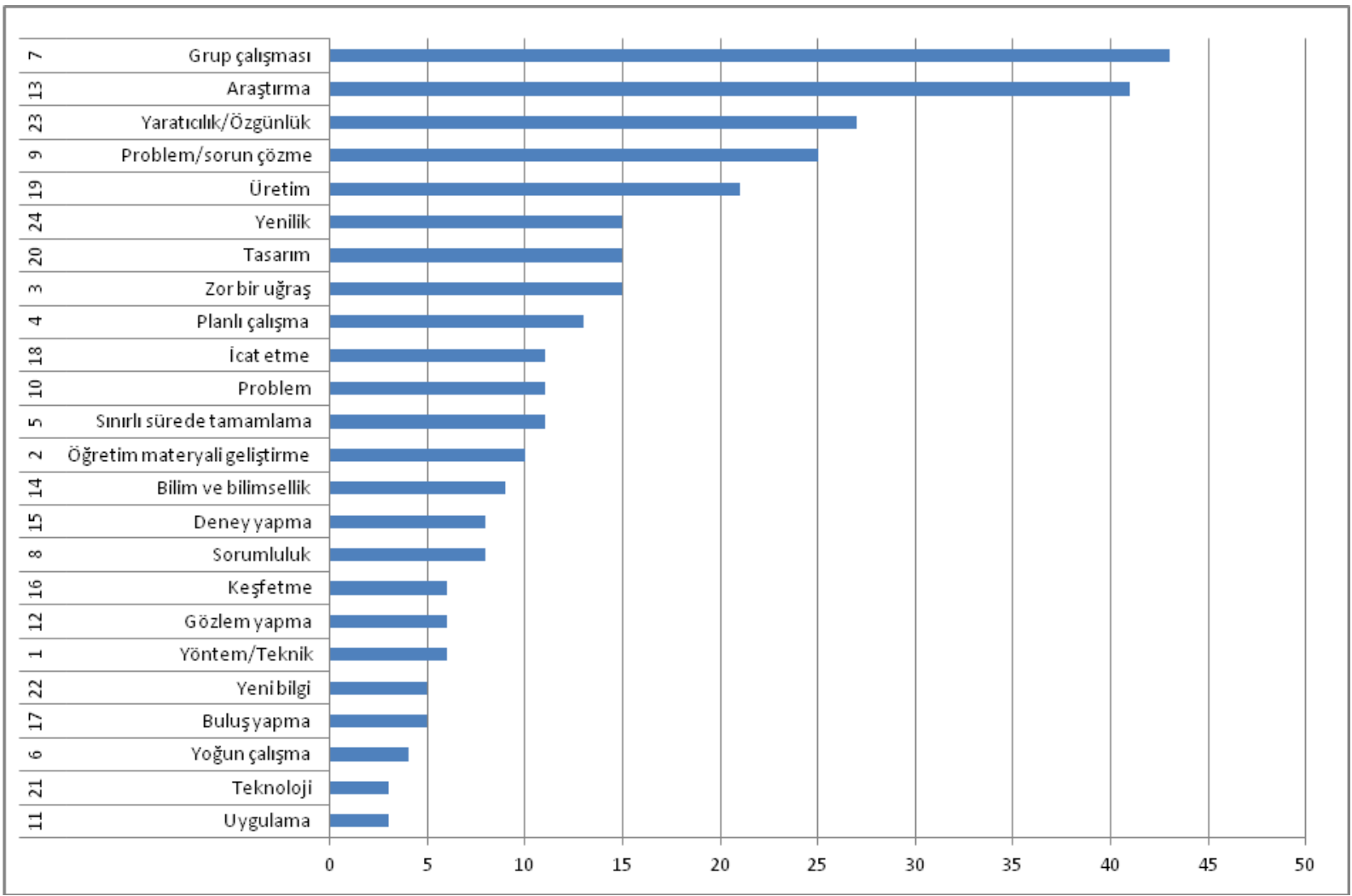

Şekil 1. Projeyi ifade eden kelimler ve tekrar edilme sıklıklarının grafikle gösterimi

Tablo 1 ve Şekil 1'de görüldüğü gibi proje kavramının anlamı ile ilgili 24 ifade tespit edilmiştir. Bu ifadeler belirli özelliklerine göre gruplandırılarak 8 tema belirlenmiștir.

İfadeler ve temalar arasındaki ilişkiyi gösteren model ise Şekil 2'de görülmektedir. 
YYÜ Eğitim Fakültesi Dergisi (YYU Journal of Education Faculty), 2019; 16(1):678-693, http://efdergi.yyu.edu.tr

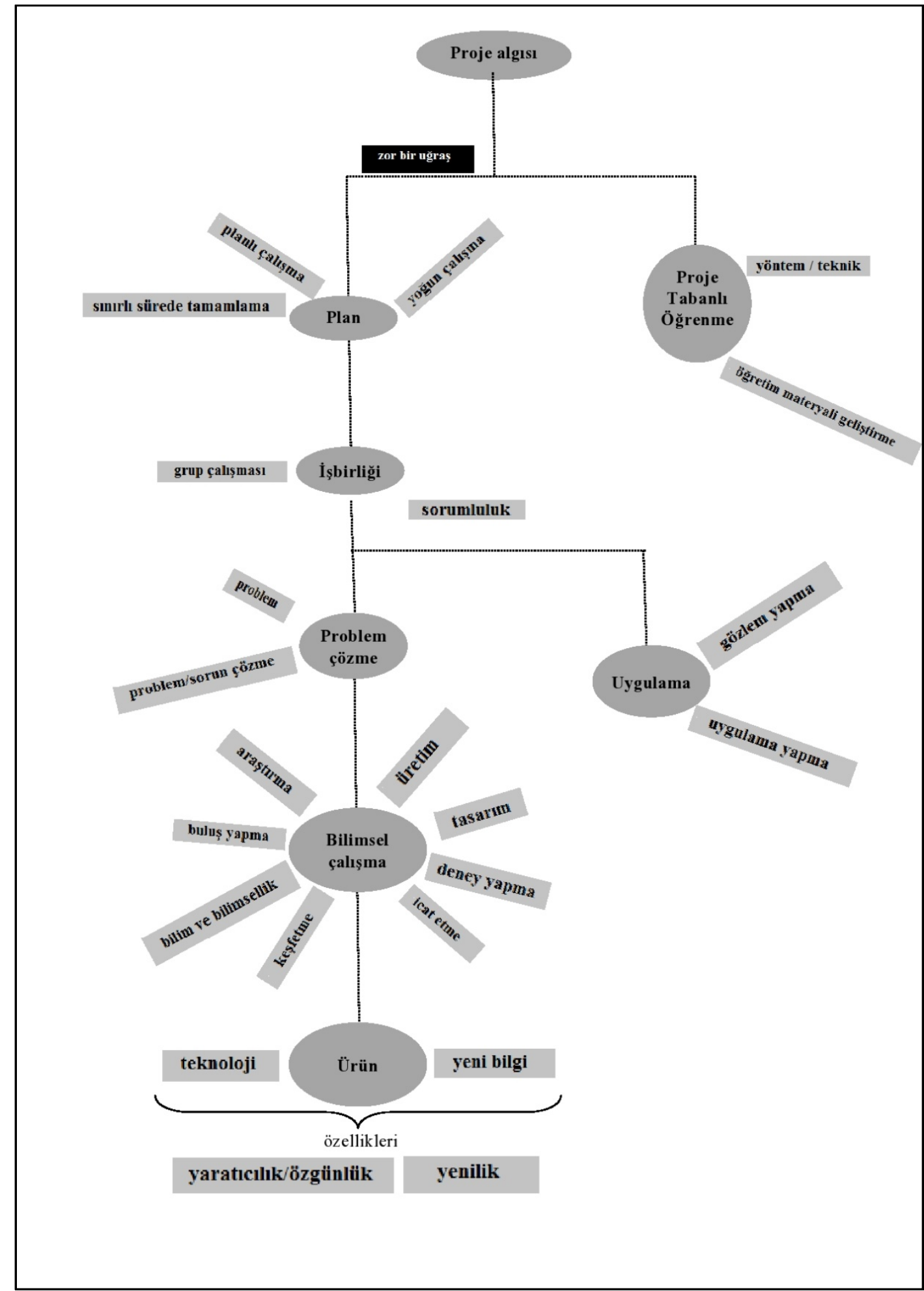

Şekil 2. Proje algıları ve temalar arasındaki ilişkiyi gösteren model

Temalar incelendiğinde (Şekil 2) temelde iki gruba ayrıldıkları görülmektedir. Bir başka ifade ile sosyal bilgiler öğretmen adaylarına göre proje temelde iki anlam ifade etmektedir. 
Birincisinde proje kavramına derste kullanılan bir yöntem/teknik veya öğretim materyali tasarlamak anlamları yüklenmiştir. $\mathrm{Bu}$ iki anlam projeler kullanılarak öğrenme amaçlarının edindirmesine katkı sağlamak şeklinde kısaca tanımlanabilen PTÖ başlığı altına yerleştirilmiştir. Tablo 1'de görüldüğü gibi projeyi yöntem/teknik olarak algılayan altı, öğretim materyali tasarlamak şeklinde algılayanların 10 öğretmen adayı olduğu görülmektedir.

İkincisinde proje genel olarak bilimsel bir araştırmanın özellikleri ve aşamaları şeklinde algılanmış ve böyle bir çalışmayı yapmanın (proje yapmanın ) çok zor olduğu vurgulanmıştır $(\mathrm{f}=15)$. Burada proje planlı çalışma, işbirliği yapma, problem çözme, uygulamalar yapma, bilimsel çalışma, özgün ve yenilikçi bir ürün ortaya koyma şeklinde ifade edilmiştir. Planlı çalışma teması, planlı çalışma ( $\mathrm{f}=13)$, sınırlı sürede tamamlama $(\mathrm{f}=11)$ ve yoğun çalışma ( $\mathrm{f}=4)$ ifadelerini içermektedir. İşbirliği isimli tema grup çalışması $(\mathrm{f}=43)$ ve sorumluluk $(\mathrm{f}=8)$ ifadelerinden oluşurken, problem isimli tema problem/sorun çözme (f=25) ve problem (f=11) ifadelerini içermektedir. Projenin uygulama yapmak olduğunu düşünenlerin ifadeleri uygulama teması altına toplanmış ve uygulama $(\mathrm{f}=3)$ ve gözlem yapma $(f=6)$ ifadeleri bu tema altında toplanmıştır. Bilimsel çalışma isimli tema altında araştırma ( $f=41$ ), bilim ve bilimsellik $(f=9)$, deney yapma ( $f=8)$, keşfetme $(f=6)$, buluş yapma ( $\mathrm{f}=5)$, icat etme $(\mathrm{f}=11)$, üretim $(\mathrm{f}=21)$ ve tasarım $(\mathrm{f}=15)$ olmak üzere 8 ifade bulunmaktadır. Son tema olan ürün isimli temanın içinde teknoloji ( $\mathrm{f}=3)$ ve yeni bilgi $(\mathrm{f}=5)$ ifadeleri bulunmaktadır. Ürün isimli tema ile ilgili olarak ürün özellikleri de bir tema olarak belirlenmiştir. Yaratıcılık (özgünlük) $(\mathrm{f}=27)$ ve yenilik $(\mathrm{f}=15)$ ürün özellikleri temasının içinde yer alan ifadelerdir.

\section{Tartışma, Sonuç ve Öneriler}

Proje konusunda yeterli deneyime sahip olmayan sosyal bilgiler öğretmen adaylarının sahip oldukları proje algılarını ortaya çıkarmanın amaçlandığı bu çalışmada tartışma projenin literatürde sahip olması gereken özellikler ile bu çalışmada ortaya çıkan özelliklerin kıyaslanması şeklinde yürütülmüştür.

Proje konusunda deneyimi olmayan sosyal bilgiler öğretmen adaylarının proje algıları olarak 24 ifade ve 8 tema tespit edilmiştir (Tablo 1 ve Şekil 1). Bunlar Marshall vd. (2011) tarafından ortaya çıkarılan ve proje deneyimine sahip olan öğretmen adaylarının proje algılarını konu alan bulgular ile kıyaslandığında plan, işbirliği, problem, bilimsel çalışma ve 
ürün temalarının ortak olduğu, her iki durumda proje algılamalarının büyük ölçüde benzerlik gösterdiği görülmektedir. Ancak daha önce proje deneyimi olan öğretmen adaylarının bu çalışmada ortaya çıkan durumdan farklı olarak uzun süreli olması, günlük yaşamla ilgili olması, ilgi çekici bir konu içermesi gibi ifadeler kullandıkları ve bunların projenin karakteristik özellikleri arasında yer aldığı tespit edilmiştir (Marshall vd., 2011). Buradan hareketle proje deneyimi olan öğretmen adayları ile olmayan öğretmen adaylarının benzer proje algılamalarına sahip olduğu, ancak proje deneyimi olmayanların projenin karakteristik özelliklerini (örneğin proje-günlük yaşam ilişkisi) göz ardı ettikleri sonucuna ulaşılmıştır.

Sosyal bilgiler öğretmen adaylarının proje algılarını gösteren model (Şekil 2) incelendiğinde bazı öğretmen adaylarının proje ile PTÖ’yü aynı anlamda kullandığı görülmektedir. $\mathrm{Bu}$ öğretmen adaylarına göre proje, bir öğretim materyali tasarlamak veya derste kazanımları edindirmek için kullanılan bir yöntem veya tekniktir. Bu çalışmada sözü edilen ve sorgulanan proje öğretmen adaylarının öğretmenlik yaşantılarında karşılaştıkları mesleki sorunları çözmek için kullanılan bilimsel araştırma yöntemidir. Bu durum öğretmen adaylarının proje deneyimine sahip olmamasına rağmen lisans eğitimlerinde aldıkları öğretim teknolojileri ve materyal tasarımı veya özel öğretim yöntemleri gibi derslerde öğretim amaçlı yaptıkları uygulamaları proje olarak adlandırmalarından kaynaklandığı düşünülmektedir. Daha önce de ifade edildiği gibi, proje öğrenmeye katkı sağlamak amacıyla kullanıldığında PTÖ olarak adlandırılır ve PTÖ projeye benzemesine rağmen ondan farklı bir anlam ifade etmektedir (Wengrowicz vd., 2014). Bu bağlamda, proje konusunda deneyimi olmayan sosyal bilgiler öğretmen adaylarından bir kısmının proje ile PTÖ’yü birbirinden ayırt edemedikleri sonucuna ulaşılmıştır.

Öğretmen adaylarının proje konusundaki algılarını gösteren model incelendiğinde (Şekil 2), projenin bilimsel bir araştırmanın özelliklerini içerdiği, plan, işbirliği, problem çözme, bilimsel çalışma ve ürün gibi boyutlara sahip olduğu görülmektedir. Bilimsel çalışma boyutu içinde araştırma, bilim ve bilimsellik, deney yapma, keşfetme, buluş yapma, icat etme, üretim ve tasarım gibi pozitif bilimlerde projeyi ifade etmek için tercih edilen ifadelerin kullanıldığg dikkati çekmiştir. Bu durum sosyal bilgiler öğretmen adaylarının projeyi pozitif bilimlere ait bir olgu olarak gördükleri şeklinde yorumlanabilir. Pozitif bilimlerde bilimsel araştırma ve proje hazırlamanın sosyal bilimler ile kıyaslandığında çok daha önce başladığı bilinmektedir (Ekiz, 2006). Bu nedenle içinde yaşanılan çevrede pozitif bilimlere ait proje örnekleri veya proje ürünlerinin kullanımına yönelik yansımaların daha fazla olduğu görülmektedir. Çalışmanın örneklemini oluşturan öğretmen adayları proje deneyimine sahip 
olmadıkları için, pozitif bilimlere ait projelerin toplum içindeki yansımalarından etkilendiği anlaşılmaktadır. $\mathrm{Bu}$ noktadan hareketle proje deneyimine sahip olmayan öğretmen adaylarının çevrelerindeki pozitif bilimlere ait proje örneklerinden etkilendikleri için projeyi pozitif bilimlere ait projeyi anımsatan ifadeler kullanarak tanımladıkları söylenebilir.

Proje algısına yönelik grup çalışması yapma, araştırma, yaratıcılık/özgünlük, problem/sorun çözme ve üretim ifadelerinin diğerleri ile kıyaslandığından çok fazla kullanıldığı görülmektedir (Tablo 1, Şekil 1). Krajcik (2015) tarafından belirtilen ve bir projenin sahip olması gereken 5 özelliği (günlük yaşamla ilişkili olma, problem çözme, işbirliği, ürün ortaya çıkarma ve teknolojiyi kullanma) göz önünde bulundurulduğunda günlük yaşamla ilişki ve teknoloji kullanımı dışındaki diğer özelliklerin örtüştüğü görülmektedir.

Araştırmada elde edilen sonuçlar doğrultusunda sosyal bilgiler öğretim programında öğrenim gören lisans öğrencilerine proje eğitimi verilmeden önce proje algıları ortaya çıkarılması gerektiği belirtilebilir. Buna ilave olarak proje algıları ortaya çıkan ürünü etkilediği için, verilecek proje eğitimleri veya herhangi bir dersin içinde proje ve PTÖ’ ye ilişkin içeriklerin bu algılara göre şekillendirilmesi gerektiği düşünülmektedir. Öğretmen adaylarının projeyi daha çok pozitif bilimlerle örtüştüren algılarını değiştirme bağlamında, sosyal bilimlere özgü (sosyal, kültürel ve eğitim vb. konularını içeren) proje örneklerini onlara sunmanın faydalı olacağı söylenebilir. Bu kapsamda, bilimsel araştırma yöntemleri ve topluma hizmet uygulamaları gibi proje ile doğrudan ilişkili derslerde, sosyal, kültürel, ekonomik sorunları ve bunların çözümlerini konu edinen proje örnekleri öğretmen adaylarına tanıtılmalı, ilgili ders içerikleri onların proje hazırlama ve yürütme konusunda deneyim kazanmalarını sağlayacak biçimde düzenlenmelidir. Öğretmen adaylarının projenin günlük yaşamla ilişki ve teknoloji kullanımı özelliklerini göz ardı ettikleri düşünüldüğünde, günlük yaşamların kolaylaştıran birçok ürünün ortaya çıkış sürecine ve nano teknolojiden uzay teknolojisine kadar faklı ölçek ve çeşitlilikte yürüten ulusal ve uluslararası projelere yönelik ilgi ve farkındalıklarını arttırmak gerektiği söylenebilir. Bu bağlamda sosyal bilgiler öğretmenliği lisans programında yer alan Bilim, Teknoloji ve Sosyal Değişim dersi öğrencilerin bu konularda kazanımlar edineceği şeklide yapılandırılabilir ve konuyla ilgili seçmeli derslerin lisans programına eklenmesi de tartışılabilir. Öğretmen adaylarının göreve başladıklarında karşılaştıkları sorunları projeler yoluyla çözebilecekleri ve bu çözümlerini konun paydaşlarıyla raporlar/proje ürünleriyle paylaşabileceğini konusunda bilinç kazanmaları için öncelikle proje algılarının doğru ve bilimsel gerçeklere dayalı olması 
YYÜ Eğitim Fakültesi Dergisi (YYU Journal of Education Faculty), 2019; 16(1):678-693, http://efdergi.yyu.edu.tr

gerekmektedir. Onlara proje eğitimleri ve proje deneyimleri ile bu bilinç kazandırma konusunda ise asıl sorumluğun lisans programında görevli ve çağın gereklerine uygun öğretmen yetiştirme iddiasına sahip öğretim eleman/üyelerinde olduğu unutulmamalıdır. Son olarak öğretmen adaylarına proje eğitimi ve yürütme imkânı sunan derslerde (Bilimsel Araştırma Yöntemleri ve Topluma Hizmet uygulamaları gibi), eğitim/uygulama öncesi ve sonrasında öğretmen adaylarının proje algılarında yaşanan değişimi konu edinen çalışmaların alana katkı sağlayacağı düşünülmektedir.

\section{Makalenin Bilimdeki Konumu}

Türkçe ve Sosyal Bilgiler Eğitimi Bölümü/Sosyal Bilgiler Öğretmenliği Anabilim Dalı

\section{Makalenin Bilimdeki Özgünlüğü}

Öğretmen adaylarına lisans eğitimleri sırasında verilecek proje eğitimleri öncesi çeşitli proje deneyimlerine sahip olanların algıları yapılan çalışmalarla ortaya çıkarıldığı için kurs hedefleri ve içerikleri bu doğrultuda düzenlenebilir. Ancak hiç deneyimi olmayan öğretmen adaylarına uygulanacak kurs içeriğinin oluşturulması için onların proje algılarının tespit edilmesi önem arz etmektedir.

\section{Kaynaklar}

Acun, R. (2010). Üniversitelerde eğitim ve araştırma işlevlerinin entegrasyonu. Edebiyat Fakültesi Dergisi, 27(1), 1-14.

Buzan, T. (2005). Mind map handbook. Great Britain: Thorsons,

Blumenfeld, P. C., Soloway, E., Marx, R. W., Krajcik, J. S., Guzdial, M., \& Palincsar, A. (1991). Motivating project-based learning: sustaining the doing, supporting the learning. Educational Psychologist, 26(3/4), 369-398.

Bulunuz, M. (2011). Evaluation of pre-service elementary science teachers' experiences with science projects. Journal of Turkish Science Education, 8(4), 74-85.

Ekiz, D. (2006). Öğretmen ĕgitimi ve ögretimde yaklaşımlar. Ankara: Nobel Yayın ve Dağıtım.

Hou, H. (2010). Exploring the behavioural patterns in project-based learning with online discussion: quantitative content analysis and progressive sequential analysis. Turkish Online Journal of Educational Technology - TOJET, 9(3), 52-60.

Kaptan, S. (1998). Bilimsel araştırma ve istatistik teknikleri. Ankara: Tekışık Yayınları.

Karasar, N. (2014) Bilimsel araştırma yöntemi, kavramlar, ilkeler, teknikler. Ankara: Nobel Yayın Dağıtım. 
YYÜ Eğitim Fakültesi Dergisi (YYU Journal of Education Faculty), 2019; 16(1):678-693, http://efdergi.yyu.edu.tr

Karışan, D. ve Bakırcı, H. (2018). Öğretmen adaylarının FeTeMM öğretim yönelimlerinin anabilim dalına ve sınıf düzeyine göre incelenmesi. Adlyaman Üniversitesi Ĕ̈itim Bilimleri Dergisi, 8(2), 152-175.

Krajcik, J. (2015). Project-based science: engaging students in three-dimensional learning. The Science Teacher, 82(1), 25-27.

Marshall, J. A., Petrosino, A. J., \& Martin, T. (2010). Preservice teachers' conceptions and enactments of project-based instruction. Journal of Science Education and Technology, 19, 370-386.

Metz, S. (2015). Project-based science learning. The Science Teacher, 82(1), 6.

Miles, M. B., Huberman, A. M., \& Saldana, J. (2015). Qualitative data analysis. A methods source book. USA: Sage publications.

Önen, F., Mertoğlu, H., Saka, M. \& Gürdal, A. (2010). Hizmet içi eğitimin öğretmenlerin proje ve proje tabanlı öğrenmeye ilişkin bilgilerine ve proje yapma yeterliklerine etkisi: ÖPYEP örneği. Ahi Evran Üniversitesi Eğitim Fakültesi Dergisi, 11(1), 137-158.

Rogers, M. A. P., Cross, D. I., Gresalfi, M. S., Trauth-Nare, A. E., \& Buck, G. A. (2010). First year implementation of a project-based learning approach: The need for addressing teachers' orientations in the era of reform. International Journal of Science and mathematics Education, 9(4), 893-917. doi:https://doi.org/10.1007/s10763-0109248-X

URL-1, (2018). 21st Century student outcomes and support systems. http://www.battelleforkids.org/networks/p21/21st-century-learning-exemplar-program.

Wengrowicz, N., Dori, D., \& Dori, Y. J. (2014). Clarity and understandability of two modeling langugaes in a large-scale project-based information systems engineering course. NARST 2014 Annual International Conference, Pittsburgh, PA, USA., 30 March-02 April.

Yin, R. K. (2003). Case study research: Design and methods. Thousand Oaks, Calif: Sage Publications.

Zafirov, C. (2013). New challenges for the project based learning in the digital age. Trakia Journal of Sciences, 11(3), 298-302.

\section{Summary}

\section{Problem Statement}

Project-Based Learning (PBL) actively incorporates students -from kindergarten to university (K-12)- into everyday life through projects and offers important opportunities for 
YYÜ Eğitim Fakültesi Dergisi (YYU Journal of Education Faculty), 2019; 16(1):678-693, http://efdergi.yyu.edu.tr

the acquisition of 21st-century skills (Metz, 2015). Projects, which are the focus of PBL (Wengrowicz et al., 2014), can be used to contribute to learning, as well as to solve problems that teachers face in their classrooms.

Pre-service teachers should get insights into increasingly popular notions of PBL and project before entering the profession (Zafirov, 2013; Hou et al., 2010). If pre-service teachers use the project approach during their undergraduate study or do research, it contributes to solving problems they face in the teaching profession. Acun (2010) argues that learning how to do research is actually learning how to learn. The author further notes that there are today very rapid changes in knowledge accumulation and gaining skills alone is not enough; thus, professionals who know how to learn (i.e. how to do research) are more successful than others.

The purpose of this study is to explore projects perceptions of pre-service social studies teachers who have no project experience and have never conducted scientific research so far.

\section{Methods}

The survey research method was used in the study. Survey research is a type of descriptive research methods that allows a detailed representation of an event, phenomenon or situation in numbers or words. The survey model is implemented using frequencies and/or percentages to describe a situation that concerns a large number of people (Karasar, 2014).

\section{Sampling}

The sample consisted of 145 third-grade candidate teachers who study social studies teaching at the Department of Primary Education, Fatih Faculty of Education, Karadeniz Technical University.

\section{Data Collection Tools}

The data was collected using open-ended questions and mind maps drawn by the preservice teachers. Before the pre-service social studies teachers took the research medhods course, they were made to draw a mind map and write explanations and asked open-ended survey questions.

\section{Data Analysis}

Data analysis was performed using NVivo software version 9.0, and descriptive statistics. The data were presented in tables and graphs. Phrases that the pre-service teachers used on the mind map and expressions they wrote to explain them were discussed together with their responses to open-ended questions. 


\section{Results}

Phrases and expressions the pre-service social studies teachers wrote on the mind maps with respect to the project notion, as well as frequencies are presented in Table 1 and Figure 1. As shown in Table 1 and Figure 1, twenty-four phrases about the meaning of the project notion were identified. These expressions were grouped into eight themes on the basis of their specific characteristics.

When themes analyzed (Figure 2), it seems that they are basically divided into two categories. In other words, the project notion basically means two things to the pre-service social studies teachers.

First, the project notion means designing a method/technique or a teaching material used in the class. Second, the pre-service teachers generally perceive a project as the features and stages of scientific research, thereby emphasizing that it is really hard to do such research (to make a project) ( $\mathrm{f}=15$ ). Here, a project was expressed as planned work, collaboration, problem-solving, application, scientific work, as creating an original and innovative product. The theme of planned work includes the following phrases: planned work ( $f=13$ ), completing in limited time ( $\mathrm{f}=11$ ), and intensive work ( $\mathrm{f}=4$ ). The theme of collaboration includes the phrases group work $(f=43$ ) and responsibility ( $f=8)$, while the theme of problem includes problem-solving $(f=25)$ and problem ( $f=11)$. The statements of those who perceive a project as carrying out applications were subsumed under the theme of application, which includes the phrases application ( $f=3$ ) and observation ( $f=6$ ). The theme of scientific work involves the following eight phrases: research $(f=41)$, science and scientificness ( $(f=9$ ), experimentation ( $(=8)$, discovery ( $(f=6)$, invention ( $f=5$ ), invention ( $=11$ ), production $(\mathrm{f}=21)$, and design ( $\mathrm{f}=15$ ). The latest theme, product, includes technology ( $f=3$ ) and new information ( $f=5$ ). In relation to the theme of product, the product properties were also set as a theme. Creativity (originality) ( $f=27$ ) and innovation ( $f=15$ ) are the phrases under the theme of product properties.

\section{Discussion and Conclusions}

24 phrases and 8 themes were identified as project perceptions of pre-service social studies teachers who have no project experience (Table 1 and Figure 1). There are similarities between perceptions of project in this study and those described by Marshall et al. (2011) surveying a sample of pre-service teachers who have project experiences. Accordingly, the themes panned worked, cooperation, scientific work, and product are common. However, the 
YYÜ Eğitim Fakültesi Dergisi (YYU Journal of Education Faculty), 2019; 16(1):678-693, http://efdergi.yyu.edu.tr

authors also reported expressions such as spanning a long period of time, related to everyday life, and dealing with an interesting topic, which all are among the characteristics of the project. These differences may be due to the fact that unlike the sample of the present study, the pre-service teachers in their study had project experiences. It can, therefore, be assumed that pre-service teacher who have project experiences and those who have no project experience share similar perceptions of project; however, those who have no project experience disregard the characteristics of a project (e.g.project-everyday life association)

Group work, research, creativity/originality, problem/problem solving, and production are the most frequent phrases in relation to perceptions of project (Table 1, Figure 1). Considering the five features that Krajcik (2015) considers a project must have (being associated with everyday life, problem-solving, collaboration, product creation, and technology use), the findings of the present study are consistent with the features other than association with everyday life and technology use. It thus seems that that pre-service teachers' perceptions of project are close to what they should be, but do not include the aspects of everyday life and technology use.

The results obtained from this study suggest that before undergraduate students studying social studies teaching are given project training, their perceptions of project should be explored. Additionally, perceptions of project should be taken into consideration in designing project training and course contents about projects and PBL, since they impact on products. 